\title{
Acidentes de trabalho nas principais atividades do setor agrícola no Brasil entre 2013 e 2018
}

A agricultura é uns dos setores econômicos mais importante do Brasil e consequentemente é um dos que mais empregam, no entanto, devido as atividades executadas serem de alta periculosidade e ocorrerem muitas vezes em ambientes pouco salubres, a ocorrência de acidentes nesses meios são elevados, assim o objetivo do presente estudo é analisar os dados de acidentes do trabalho para a agricultura, considerando as 5 primeiras atividades que apresentam os maiores números em registro de acidentes. Foi utilizado para a análise os anuários estatísticos previdenciários sociais (AEPS) para o período de 2013 a 2018 , buscando levantar o perfil acidentário das vítimas e quais estados da união mais contribuem com os números de acidentados no país, com o objetivo de levantar um panorama geral dos acidentes do trabalho no setor agrícola, assim compilando dados para facilitar a aplicação de programas que promovam a prevenção de acidentes no campo. Através da análise dos dados foi encontrado que o trabalhador do sexo masculino, geralmente ocupando uma vaga de auxiliar de campo, representa a maior parcela dos acidentes registrados no INSS. As lesões ocorreram em maioria nas mãos e dedos e, em alguns casos, em membros inferiores. As lesões mais comuns foram fraturas, cortes e lacerações, geralmente sem risco a vida do trabalhador. Os estados que apresentaram os maiores números de acidentes no setor agrícola foram os estados de São Paulo (SP), Mato Grosso (MT) e Mato Grosso de Sul (MS). E foi observado que a ocorrência de acidentes registrados está intimamente ligada com a produção agrícola predominante e a intensidade da atividade econômica dos estados.

Palavras-chave: Acidente de Trabalho; Acidentes no Setor Agrícola; Previdência Social; Perfil Acidentário.

\section{Analysis of occupational accident for main activities of the agricultural sector in Brazil between 2013 and 2018}

\begin{abstract}
The present study intends to analyze the data on accidents at work for agriculture considering the first 5 activities that present the highest accident record. The social security statistical yearbooks (AEPS) for the period 2013 to 2018 were used for the analysis, seeking to raise the accident profile of the victims and which states of the union most contribute to the numbers of victims in the country, with the objective of raising a panorama general of occupational accidents in the agricultural sector, thus compiling data that facilitates the application of programs that promote the prevention of accidents in the field. Through data analysis, it was found that the male worker, usually occupying a vacancy as a field assistant, is the largest share of accidents registered with the INSS. The injuries occurred mostly in the hands and fingers and, in some cases, in the lower limbs. The most common injuries were fractures, cuts and lacerations, generally without risk to the worker's life. The states that had the highest numbers of accidents in the agricultural sector were the states of São Paulo (SP), Mato Grosso (MT) and Mato Grosso de Sul (MS). And it was observed that the occurrence of registered accidents is closely linked with predominant agricultural production and the intensity of economic activity of the state.
\end{abstract}

Keywords: Occupational Accident; Accidents in the Agricultural Sector; Social Security; Accident Profile.

Topic: Políticas, Planejamento e Gestão de Sistemas e Serviços de Saúde

Reviewed anonymously in the process of blind peer.

Alexandre Assis Rezende Santos (iD) Centro Universitário de Lavras, Brasil http://lattes.cnpq.br/6951054613493121

http://orcid.org/0000-0002-0053-5385

nukereset@gmail.com

Evandro Pereira da Silva

Centro Universitário de Lavras, Brasil

http://lattes.cnpq.br/7111995291388699

evandro@unilavras.edu.br

Tamires Galvão Tavares Pereira

Centro Universitário de Lavras, Brasil

http://lattes.cnpq.br/2193131970787592

tamires florestal@hotmail.com
Received: $17 / \mathbf{1 0} / \mathbf{2 0 2 0}$

Approved: 21/01/2021

Centro Universitário de Lavras, Brasil

http://lattes.cnpq.br/1794664336140572

http://orcid.org/0000-0001-7052-0659

hercules marzoque@hotmail.com

Referencing this:

SANTOS, A. A. R.; SILVA, E. P.; PEREIRA, T. G. T.; MARZOQUE, H. J.. Acidentes de trabalho nas principais atividades do setor agrícola no Brasil entre 2013 e 2018. Scire Salutis, v.11, n.1, p.134-145, 2021. DOI: http://doi.org/10.6008/CBPC2236-9600.2021.001.0015 


\section{INTRODUÇÃO}

O Brasil é um dos maiores centros agrícolas do mundo, sendo uns dos maiores produtores de alimentos como grãos, frutas e proteína animal, na frente de diversos países da Europa e China, mas ficando atrás dos Estados Unidos na produção e exportação de alimentos em aspectos gerais. O setor agrícola emprega 12 milhões de pessoas, cerca de $14,2 \%$ da população economicamente ativa do país (SOUSA et al., 2016).

O Agronegócio é um dos setores da economia brasileira que mais empregam pessoas e também uns dos setores em que mais pessoas se acidentam e adoecem devidos às condições de trabalho. A Organização Internacional do Trabalho atribui ao trabalho agrícola um risco de acidente maior que outras ocupações, e milhões sofrem acidentes devido ao grande número de trabalhadores nessa área e a falta de treinamento (ZAWACKI, 2017).

A maioria desses acidentes ocorrem devido à combinação de fatores ambientais com riscos não controlados e a fatores humanos, por exemplo, a interação com equipamento fora das normas estabelecidas, condições ergonômicas impróprias, fadiga e más condições psicológicas do trabalhador. Ainda a combinação de baixa instrução devido à falta de ensino básico de qualidade, falta de treinamento, o que é comum nesse meio, e o uso de equipamentos antigos e sem proteção podem ocasionar acidentes extremamente graves levando a amputações e mortes (NASCIMENTO et al., 2016).

Alguns estados da federação são mais afetados do que outros em relação aos acidentes no campo, e isto deve-se ao fato de que a maioria desses estados apresentam uma matriz econômica baseada, em sua maioria, em atividades agrícolas. Isto pode ocorrer devido às questões culturais, climáticas e territoriais que o estado apresenta. Os acidentes do trabalho nessas regiões podem impactar toda cadeia produtiva local, além de trazer problemas sociais aos acidentados, já que o trabalhador rural, em sua maioria, apresenta um baixo nível de escolaridade e não tem condições de arcar com os custos de atendimento hospitalar adequado em caso de um acidente (SILVA et al., 2017). Segundo números da previdência social em 2018, o Brasil registrou cerca de 576.951 acidentes, onde 16.651 (cerca de 2,88\% do total de acidentes) ocorreram somente no setor agrícola.

Assim esse estudo teve como objetivo avaliar quais atividades agrícolas apresentam os maiores números de acidentes do trabalho (com CAT e sem CAT) e em quais regiões e estados do Brasil estão concentradas essas atividades e ainda levantar o perfil acidentário do trabalhador que é mais afetado, para assim melhor compreender quais atividades apresentam maior risco dentro setor agrícola e auxiliar na implementação de políticas mais eficazes de prevenção de acidentes dentro desse setor.

\section{MATERIAIS E MÉTODOS}

Os dados usados na avaliação dos acidentes do trabalho na agricultura foram extraídos dos anuários estatísticos da previdência social (AEPS), proveniente do INSS, dos anos de 2013 a 2018. As informações coletadas foram inseridas em uma planilha e dispostas em tabelas e gráficos com informações sobre o setor, 
usando uma abordagem descritiva. Os relatórios sempre trazem informações de 2 anos antes referentes ao ano corrente do relatório, assim, ao analisar o relatório do ano de 2018, por exemplo, também neste relatório está presente os dados dos anos de 2017 e 2016 atualizados. Assim, foram somente utilizados os relatórios dos anos de 2018, 2016 e 2014 para a obtenção dos dados. Nas análises foram considerados os dados de acidentes de trabalho com a abertura de CAT (Comunicação de acidente de Trabalho), que engloba os acidentes típicos, trajeto e doença ocupacional e também os acidentes sem abertura de CAT.

No AEPS, os acidentes estão separados por atividade econômica (CNAE), e esse código foi utilizado para definir as atividades que foram consideradas neste estudo, não havendo a necessidade de estabelecer um novo tipo de critério ou separação das atividades agrícolas. Na tabela 1 é apresentado a relação das atividades cadastradas no CNAE.

Além dos dados provenientes do AEPS, foram também utilizados os dados decorrentes do site Iniciativa Smartlab para comparar e complementar, caso necessário, os dados dos acidentes. O site Iniciativa Smartlab é uma iniciativa conjunta do MPT (Ministério Público do Trabalho) e da OIT Brasil (Organização Internacional do Trabalho) para cooperar com setores da sociedade civil e acadêmica para promoção da agenda de segurança no trabalho, disponibilizando de maneira fácil e rápida os dados estatísticos de acidentes no território brasileiro.

Para avaliar a ocorrência dos acidentes por regiões, estados e atividade econômica foi considerado uma média dos anos de 2013 a 2018 fornecendo um panorama geral do período estudo. Foi também avaliado o índice de incidência para cada 1000 vínculos, que relaciona o número de acidentes ocorridos em uma população de 1000 colaboradores que executam uma determinada ocupação. A intenção desse índice é avaliar o desempenho da segurança no trabalho de uma determinada ocupação, onde quanto maior o seu valor, mais condições inseguras são encontradas nessas atividades.

Para avaliar em quais atividades agrícolas os acidentes do trabalho ocorriam com maior frequência, foram consideradas as 5 atividades que apresentaram as maiores médias registrada nos anos de 2013 a 2018. Foi considerado somente essas cinco atividades, pois a soma dos acidentes registrados consiste em média $46 \%$ de todos acidentes ocorridos no setor agrícola, tendo assim, uma grande relevância no estudo de prevenção de acidentes.

Tabela 1: Tabela da Classificação Nacional de Atividades Econômicas para Atividades Agrícolas.

\begin{tabular}{|l|l|}
\hline \multicolumn{2}{|l|}{ Atividades do Setor Agrícola (Classificação CNAE) } \\
\hline Cultivo de Oleaginosas (exceto soja) & Criação de Animais (exceto suínos e aves) \\
\hline Cultivo de plantas de lavoura temporária & Atividades de apoio à agricultura \\
\hline Horticultura & Atividades de apoio a pecuária \\
\hline Cultivo de flores e plantas ornamentais & Atividades de pós-colheita \\
\hline Cultivo de laranja & Produção florestal - florestas plantadas \\
\hline Cultivo de uva & Produção florestal - florestas nativas \\
\hline $\begin{array}{l}\text { Cultivo de frutas de lavoura permanente } \\
\text { (exceto uva e laranja) }\end{array}$ & Atividades de apoio à produção florestal \\
\hline Cultivo de café & Pesca em água salgada \\
\hline Cultivo de cacao & Pesca em água doce \\
\hline Cultivo de plantas de lavoura permanente & Aquicultura em água salgada e salobra \\
\hline Produção de sementes certificadas & Aquicultura em água doce \\
\hline Produção de mudas & Cultivo de soja \\
\hline Criação de aves & Cultivo de fumo \\
\hline
\end{tabular}




\begin{tabular}{|l|l|}
\hline Criação de suínos & Cultivo de cana de açúcar \\
\hline Criação de caprinos e ovinos & Cultivo de algodão e de outras fibras \\
\hline Criação de animais de grande porte & Cultivo de cereais \\
\hline Criação bovina & \\
\hline
\end{tabular}

\section{DISCUSSÃO TEÓRICA}

\section{Atividades agrícolas com maiores números de acidentes do trabalho}

Na figura 1 é apresentado a totalidade de acidentes que ocorreram entre os anos de 2013 e 2018 no Brasil. Esses números consideram os acidentes com e sem abertura de CAT.

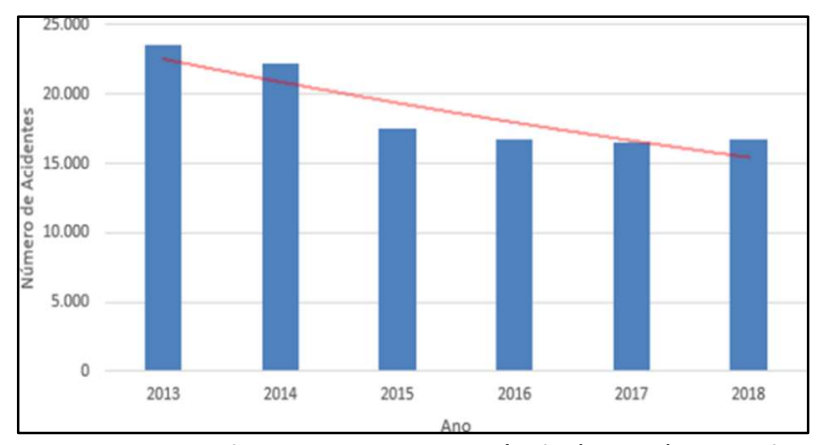

Figura 1: Acidentes no Setor Agrícola (totais) - Brasil (2013-2018).

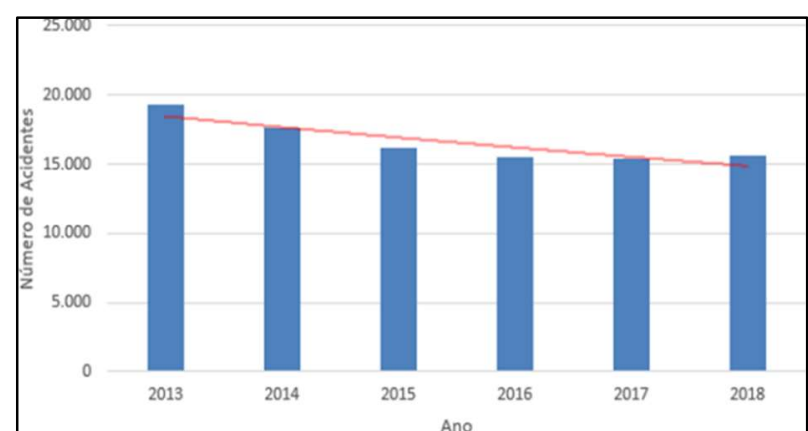

Figura 2: Acidentes no Setor Agrícola (somente CAT) Brasil (2013-2018).

Na figura 1 são ilustrados os acidentes ocorridos no setor agrícola por ano e pela curva de tendência (curva vermelha) é possível perceber uma tendência de queda do número de acidentes, no entanto se forem considerados somente os anos de 2015 em diante, os números de acidentes permaneceram praticamente constantes. Para acidentes considerando somente a abertura de CAT, figura 2, a mesma tendência de queda foi observada e a partir do ano de 2015 os números de acidentes também permaneceram praticamente constantes.

Das atividades onde se concentram os maiores casos de acidentes no meio agrícola foram separadas cinco delas, pois somente essas 5 atividades são responsáveis por cerca de $46 \%$ dos acidentes que ocorrem dentro desse setor. Na tabela 2 é apresentado os números de acidentes para essas 5 atividades considerando o período de 2013 a 2018.

Tabela 2: Número de acidentes nas 5 atividades do setor agrícola onde foram registrados mais acidentes do trabalho.

\begin{tabular}{|l|l|l|l|l|l|l|l|}
\hline Atividades do Setor Agrícola (Classificação CNAE) \\
\hline Atividades / ano & 2013 & 2014 & 2015 & 2016 & 2017 & 2018 & Média \\
\hline Cultivo de Cana de Açúcar & 4096 & 2590 & 2189 & 2104 & 1821 & 1892 & 2449 \\
\hline Criação Bovina & 3208 & 2354 & 1887 & 1723 & 1657 & 1678 & 2085 \\
\hline Produção de Sementes certificadas & 1099 & 1009 & 1412 & 1705 & 1867 & 2033 & 1521 \\
\hline Cultivo de soja & 1397 & 1273 & 1191 & 1319 & 1327 & 1423 & 1322 \\
\hline Atividades de apoio à agricultura & 1431 & 1243 & 1504 & 1284 & 1178 & 1088 & 1288 \\
\hline
\end{tabular}

Analisando essas atividades, todas apresentam um denominador em comum: são setores produtivos do Brasil que apresentam reconhecimento, tanto nacional, quanto internacional, devido a sua capacidade produtiva e qualidade dos produtos. A cana de açúcar é um grande exemplo desse reconhecimento, onde somente o Brasil produz cerca de $20 \%$ do etanol mundial, além do açúcar que é exportado para Índia, União Europeia e China (FERREIRA et al., 2018). 
A produção de carne e grãos, como a soja, é outro setor no qual o Brasil é reconhecido como um grande produtor, devido principalmente ao clima e a grande extensão territorial que possui. Além da produção de sementes que apresenta alto investimento em pesquisa por parte do setor privado e público (universidades e órgãos governamentais), que contribuem para o aumento produtivo das lavouras e resistência a pragas através de pesquisas de melhoramento genético e controle biológico, entre outras técnicas (NOCELLI et al., 2017).

Dentre todas as atividades, a maioria delas apresentaram declínio dos acidentes ocorridos ao longo do tempo. Um dos motivos para o declínio pode ser o amadurecimento dos setores agrícolas com o surgimento de empresas comprometidas em atender exigências internacionais. Fazendo com que os produtos sejam processados e colhidos, prezando pela qualidade a um preço competitivo, mas sem pôr em risco a segurança dos colaboradores.

Outro motivo para o declínio dos acidentes pode se dever ao cumprimento de exigências internas, como as normas regulamentadoras (NR's) ou em alguns casos, somente para escapar de uma punição financeira dada pelo estado, através do FAP (Fator Acidentário de Prevenção), onde o governo Federal exigem que empresas que não cuidam da saúde e segurança dos seus colaboradores paguem mais impostos para ajudar a custear aposentadorias especiais e benefícios decorrentes de acidentes de trabalho (SANTOS, 2017).

Tais medidas são importantes e Herrera (2019) demostrou isso em seu trabalho quanto a aplicabilidade delas ao setor sucroalcooleiro. Segundo ela o MPT (Ministério Público do Trabalho) realizou diversas operações para apontar irregularidades nos serviços e também em usinas que operavam em regime de semiescravidão. E traçou um paralelo com os dias atuais e avaliou o avanço que o setor sucroalcooleiro obteve com o surgimento dessas novas empresas e dessas novas regras.

Sobre outro aspecto a crise de 2014/2015 também pode ter uma parcela de culpa na redução dos acidentes, visto que houveram demissões em quantidades expressivas, reduzindo a mão de obra necessária nas empresas, e consequentemente reduzindo a ocorrência de acidentes. No entanto, a mesma tendência de queda não é observada na produção de sementes. Ao longo do tempo houve um crescimento quase linear do número de acidentes, onde de 2013 a 2018 o número de acidentes dobrou.

Não foi possível verificar o real motivo desse aumento no número de acidentes por meio de estudos, no entanto usando o observatório de segurança e saúde do trabalho, da iniciativa Smartlab, é possível traçar um perfil dos acidentes ocorridos. Segundo os dados do observatório a fratura é o tipo de acidente que mais ocorreu no setor de produção de sementes no período de 2013 a 2018, essas fraturas são localizadas nos dedos, pés e ombros e foram ocasionados por animais, não sendo especificado nos dados o tipo de animal que gerou a ocorrência. Os trabalhadores ocupavam o cargo de trabalhador agropecuário, ou seja, faziam trabalhos gerais no campo.

Na figura 3 é apresentado o aumento do número de casos com animais no período de 2013 a 2018, enquanto os outros motivos permanecem constantes ou em queda. Assim para evitar o aumento de ocorrência de acidentes no setor de sementes, é necessário que medidas preventivas devam ser tomadas no 
sentido de prevenir acidentes com animais, já que é o único tipo de acidente que apresenta uma tendência de crescimento no setor de produção de sementes.

A maioria dos acidentes que ocorrem nas 5 maiores atividades do setor agrícola são classificados como acidentes típicos e são mais de $80 \%$ dos acidentes relatados. Na figura 4 é observada uma redução da ocorrência desses acidentes para todas atividades, exceto para produção de sementes.

No entanto, essa tendência de redução não pode ser observada em outros tipos de acidentes. Nas figuras 5 e 6 são apresentadas as ocorrências de acidentes de trajeto e de doenças do trabalho. Em algumas atividades os acidentes de trajeto e de doenças do trabalho apresentam aparente tendência de queda, em outras tendências de subida ou constância. Essas tendências dependem do tipo de atividades que são executadas.

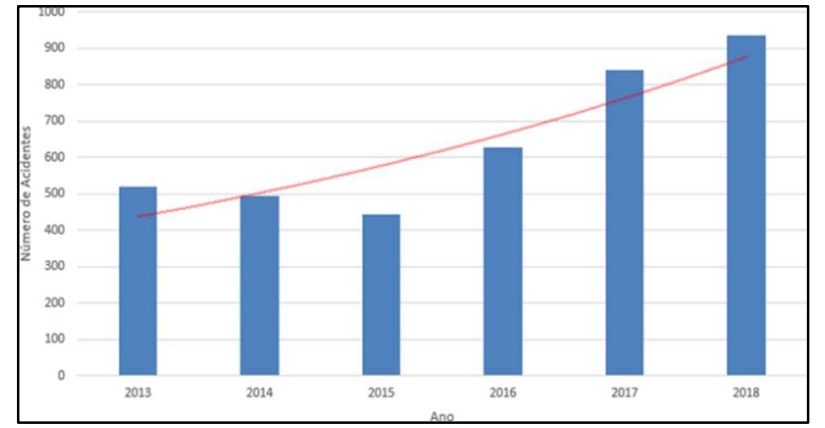

Figura 3: Número de acidentes causada por animais Centro-Oeste (2013-2018).

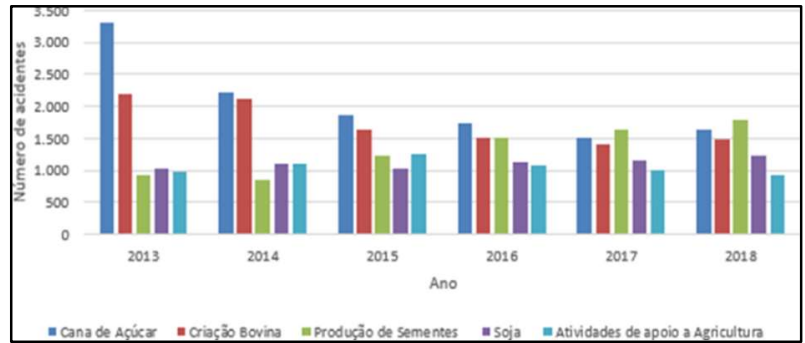

Figura 4: Número de acidentes na Agricultura (5 maiores áreas) - Acidentes Típicos.

Para os casos de acidentes de trajeto, em algumas atividades é necessário o transporte de pessoas por longas distâncias em rodovias e estradas, o que contribui para a ocorrência desse tipo de acidente, devido ao aumento de variáveis de incerteza, o que torna difícil o controle dos riscos e ainda torna a ocorrência desse tipo de acidente bastante irregulares, podendo aumentarem ou diminuírem de um ano para outro sem um motivo aparente.

Silva (2019) também perceberam tais flutuações principalmente em acidentes de trajetos, onde esses acidentes podem ser considerados como acidentes de trânsito comuns, podendo assim trazer essa variação. O uso de motocicletas em deslocamentos também tem contribuído para esse tipo de anormalidade.

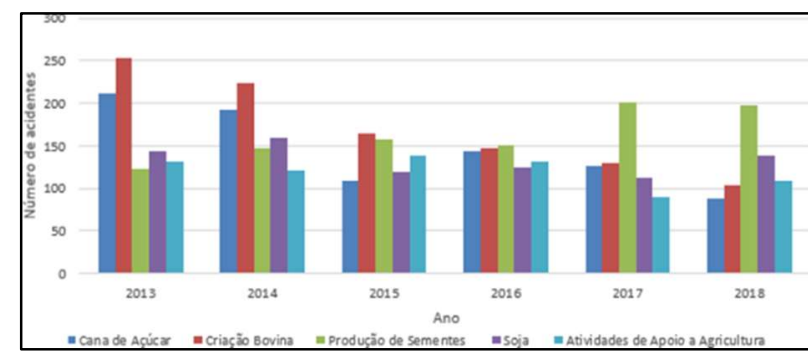

Figura 5: Número de acidentes na Agricultura (5 maiores áreas) - Acidentes de Trajeto.

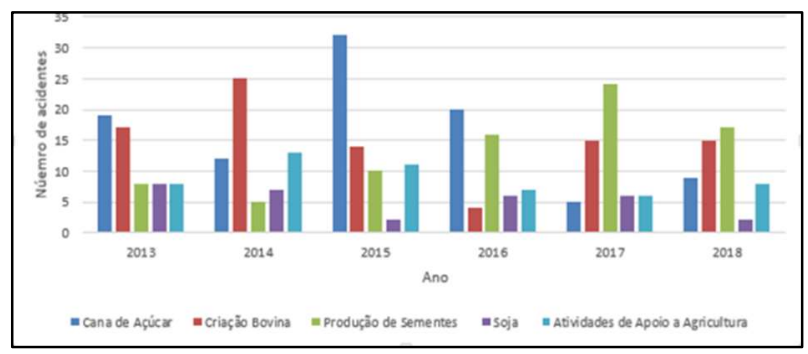

Figura 6: Número de acidentes na Agricultura (5 maiores áreas) - Doença do Trabalho.

Sieminkoski (2017) obteve respostas similares ao analisar os dados de acidentes para os setores da economia do Brasil. Foi usado no estudo de Sieminkoski (2017), um banco de dados de 2009 a 2015 e algoritmos de modelagem do tipo ARIMA e SARIMA de previsão, para estimar a tendência da ocorrência dos 
acidentes com CAT para as 3 categorias de acidentes: típico, trajeto e doença ocupacional. 0 setor agrícola de maneira geral para os acidentes com abertura de CAT apresenta tendência de queda para os 3 tipos categorias de acidentes (Típico, Trajeto e Doença do Trabalho).

Para os acidentes de trajeto e doenças do trabalho os resultados também apresentaram respostas similares para as 5 atividades estudadas, a única diferença foi nos acidentes de trajeto que apresentaram uma leve tendência de alta. Neste trabalho, apesar da abordagem descritiva e de aspectos gerais, não podemos afirmar a tendência geral dos acidentes, uma vez que nas 5 atividades estudadas cada atividade existe tendências distintas, não havendo um padrão.

\section{Estados com maior número de acidentes}

Analisando os dados do AEPS é observado que o sudeste, centro-oeste e sul são as regiões que apresentam o maior número de acidentes de trabalhos no setor agrícola. Na tabela 3 é apresentado a proporção de acidentes cometidos nas regiões onde se concentra o maior número de acidentes para as 5 atividades com mais acidentes.

Como pode ser observado as regiões sudeste e centro-oeste são as regiões que apresentam os maiores números de acidentes na agricultura. Em alguns casos somente essas duas regiões são responsáveis por mais 70\% dos casos. Essa proporção, de certa forma, já é esperada devido a intensa dinâmica econômica das regiões e por serem também conhecidas como as maiores zonas produtoras de ativos agrícolas do Brasil. Essas regiões conseguem gerar em torno de 260 bilhões de reais somente com a produção desses commodities (IBGE, 2020).

Tabela 3: Maiores representantes por região para as 5 atividades que mais registraram acidentes.

\begin{tabular}{|l|l|l|l|l|}
\hline Atividades & Maior Representante & Proporção & $2^{\circ}$ Maior Representante & Proporção \\
\hline Cultivo de cana de Açúcar & Sudeste & $63,85 \%$ & Centro-Oeste & $15,21 \%$ \\
\hline Criação bovina & Centro-Oeste & $41,00 \%$ & Sudeste & $31,31 \%$ \\
\hline Produção de sementes Certificadas & Centro-Oeste & $46,83 \%$ & Sudeste & $27,07 \%$ \\
\hline Cultivo de soja & Centro-Oeste & $70,61 \%$ & Sul & $9,96 \%$ \\
\hline Atividade de apoio à Agricultura & Sudeste & $50,80 \%$ & Sul & $25,29 \%$ \\
\hline
\end{tabular}

Para o cultivo da cana de açúcar, que é a atividade que há maior índice de acidentes na agricultura, estão dispostos na tabela 4 qual é a participação dos dois maiores representantes no número de acidentes em suas respectivas regiões.

Tabela 4: Comparação entre regiões e estados para o cultivo de cana de açúcar.

\begin{tabular}{|l|l|l|l|l|l|}
\hline \multicolumn{4}{|l|}{ Cultivo de Cana de Açúcar no Sudeste } & \multicolumn{4}{l|}{ Cultivo de Cana de Açúcar no Centro-Oeste } \\
\hline Estado & Proporção & Média & Estado & Proporção & Média \\
\hline SP & $90,09 \%$ & 1409 & MT & $11,68 \%$ & 44 \\
\hline MG & $6,05 \%$ & 57 & MS & $30,88 \%$ & 115 \\
\hline ES & $2,27 \%$ & 5 & GO & $57,43 \%$ & 214 \\
\hline RJ & $1,57 \%$ & 9 & & & \\
\hline
\end{tabular}

Os estados de São Paulo (SP) e Goiás (GO) são os dois estados que em números absolutos no Brasil apresentam os maiores números de acidentes no cultivo de cana de açúcar. A produção dessa commoditie anual para o estado de São Paulo (SP) é de 358.438.815 toneladas e 73.448.244 toneladas para o estado de 
Goiás (GO). Analisando a taxa de incidência de acidentes para cada 1000 vínculos, tem-se que que o estado de São Paulo (SP) apresenta um menor índice de incidência, com uma média de 18,37 acidentes em cada 1000 trabalhadores que executam essa função em relação a Goiás (GO), com o índice de 22,06.

Os dados revelam que embora São Paulo (SP) contenha um grande número de colaboradores no setor canavieiro, apresentando um maior número absoluto de acidentes, o estado consegue manter o nível melhor de prevenção dos seus colaboradores em relação a Goiás (GO), que é segundo no número de acidentes no setor canavieiro. Os acidentes em ambos lugares apresentam as mesmas características, onde cortes, lacerações e fraturas são os tipos de lesões mais frequentes e são localizadas nas mãos e membros superiores. Geralmente essas lesões ocorrem pelo uso de ferramentas e máquinas agrícolas. E os principais afetados são homens, principalmente com idade superior a 34 anos.

Nascimento et al. (2016) obteve resultados parecidos, no entanto seu trabalho foi realizado somente com dados do estado do Mato Grosso (MT). Os homens também eram os mais afetados na realização das atividades agrícolas, e o cultivo de plantas, mais especificamente a cana-de-açúcar e soja, são as atividades agrícolas que mais registram acidentes do trabalho. Entre as idades de 18 a 59 anos, 89,4\% dos acidentes registrados são de homens, e 94,2\% não-brancos. E o cultivo da cana-de-açúcar é responsável pelos acidentes mais graves nas atividades agrícolas.

Para a atividade de Criação bovina os dois mais afetados são os estados de Mato Grosso do Sul (MS) e São Paulo (SP). Como a criação de gado é uma atividade bastante difundida em todo território nacional, os números de acidentes são parecidos. Por exemplo, as médias dos acidentes nos anos de 2013-2018 para os estados de São Paulo (SP), Mato Grosso (MT), Mato Grosso do Sul (MS) e Minas Gerais (MG) são bem próximas, onde a diferença das médias de acidentes entre o primeiro e o último entre esses 4 estados são de 21 unidades. Na tabela 5 é apresentado a distribuição dos acidentes para criação bovina de cada estado.

Tabela 5: Estados com maior número de acidentes em média na criação bovina.

\begin{tabular}{|l|l|}
\hline Criação Bovina & Média \\
\hline Estado & 323 \\
\hline MS & 320 \\
\hline SP & 316 \\
\hline MT & 302 \\
\hline MG & \\
\hline
\end{tabular}

A taxa de incidência de acidente para cada 1000 vínculos também é bastante semelhante entre os estados, onde em Mato Grosso do Sul (MS) o valor é de 8,84 e em São Paulo (SP) esse valor é de 8,95. No entanto analisando o gráfico na figura 7 percebe se que no ano de 2018 houve uma redução acentuada nos números de acidentes no Mato Grosso do Sul (MS). Isso pode se dever a adoção de medidas governamentais a nível estadual para ajudar a produtores a terem melhores condições na criação de bovinos.

O estado do Mato Grosso do Sul (MS), por exemplo, tem um programa de auxílio nomeado de "Precoce MS" que ajuda os produtores a obter melhores resultados na criação de gado, e uma das métricas desse programa envolve a segurança do trabalhador na execução dessa atividade. Esse programa já existia a mais de 28 anos, no entanto em 2016 ele foi reformulado para melhor atender os produtores. Para o estado de São Paulo (SP) foi notado um leve aumento no 2018. No entanto, se comparados aos últimos 4 anos esse 
aumento está dentro da faixa, não caracterizando nenhum descontrole na ocorrência de acidentes ${ }^{1}$.

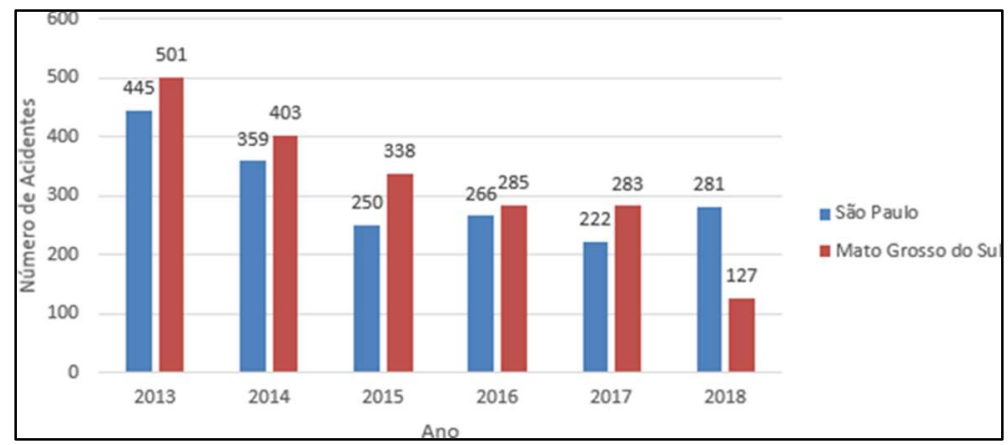

Figura 7: Comparativo do número de acidentes - São Paulo (SP) e Mato Grosso do Sul (MS) (Criação Bovina).

Os ferimentos são mais localizados em membros superiores e inferiores, sendo o principal agente causador é classificado com agente biológico (gerado por ataques de animais). Os danos mais frequentes são contusões e lacerações, e geralmente os homens são os que mais sofrem acidentes nesse meio devido a cultura do campo.

A terceira atividade responsável pelos maiores números de acidentes no setor agrícola é a produção de sementes. Como mostrado anteriormente essa é a única atividade, das utilizadas no estudo, que apresenta uma tendência de crescimento, como apresentado na tabela 6. O Centro-Oeste e Sudeste são as duas regiões foco para a ocorrência de acidentes no setor de produção de sementes. No entanto, os dois principais estados em que mais registrou ocorrências são o estado do Mato Grosso (MT) e Goiás (GO) e ambos estão localizados na região Centro-Oeste.

Tabela 6: Estados com os maiores números de acidentes em média para a produção de sementes.

\begin{tabular}{|l|l|}
\hline Produção de sementes no Centro-Oeste \\
\hline Estado & Média \\
\hline MT & 274 \\
\hline MS & 206 \\
\hline GO & 228 \\
\hline
\end{tabular}

Como dito anteriormente as lesões nessa atividade ocorrem, geralmente, nos membros superiores e são, na maioria dos casos, acidentes não fatais. Entre o período de 2013 a 2018 foram registradas 19 mortes. Embora a gravidade dos ferimentos não ponha em risco a vida dos trabalhadores, há um aumento do número de acidentes não somente no estado do Mato Grosso (MT), que detém o maior número de acidentes, mas os outros estados da região seguem o mesmo padrão. Os relatórios do INSS não deixam claros os motivos desse aumento, mas conhecendo o que ocasiona esses acidentes, podem ser estabelecidos procedimentos para evitar que ocorram. A média da incidência por cada 1000 vínculos entre 2013 e 2018 em ambos os estados também são bem altos, mas se comparado aos últimos 4 anos não há uma tendência de aumento.

No cultivo da soja, as regiões que mais se destacam são o Centro-Oeste e o Sul, onde somente o Centro-Oeste apresentando mais $70 \%$ de todos acidentes registrados do setor. 0 estado que apresenta a maior participação no número de acidentes é o estado do Mato Grosso (MT) com números absolutos médios

${ }^{1}$ http://www.precoce.semagro.ms.gov.br/ 
de 764 acidentes registrados. O estado de Goiás (GO) vem em segundo registrando pouco menos de 100 acidentes em média ao longo do período de 2013 a 2018. Grande parte do grande número desses acidentes no estado de Mato Grosso (MT) deve-se ao fato do estado ser o maior produtor de soja do país. Na figura 8 é possível notar uma leve tendência de alta ao longo do período analisado.

Tabela 7: Estados com os maiores números de acidentes em média para o cultivo de soja.

\begin{tabular}{|l|l|}
\hline Cultivo de soja no Centro-Oeste & Média \\
\hline Estado & 794 \\
\hline MT & 78 \\
\hline MS & 96 \\
\hline GO & \\
\hline
\end{tabular}

A maioria dos acidentados apresenta como lesão fraturas geralmente localizadas nas mãos e dedos. Cortes e lacerações também estão presentes, mas em menor frequência e os acidentes não há muitas ocorrências de mortes. $O$ índice de incidência por cada 1000 vínculos apresenta uma média de 21,09 acidentes, o que pode ser considerado baixo em vista da grande produção do estado no cultivo de soja (32,5 milhões de toneladas). O principal agente causador dos acidentes é a máquina agrícola e o uso de motocicletas e motonetas para o transporte (IBGE, 2020).

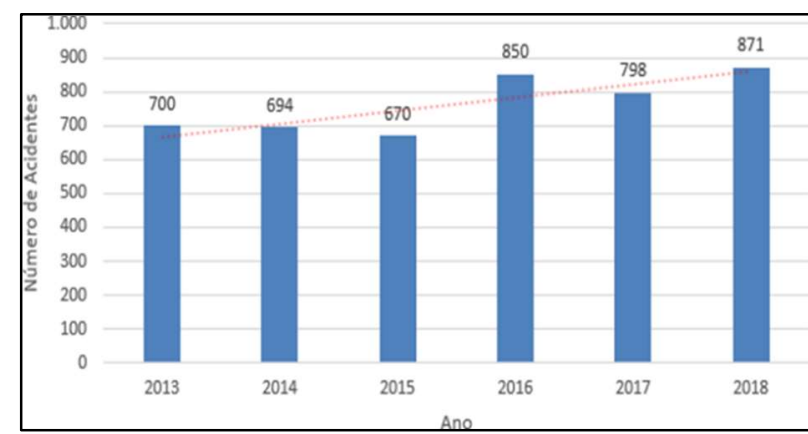

Figura 8: Número de acidentes no Mato Grosso (MT) (Cultivo de soja).

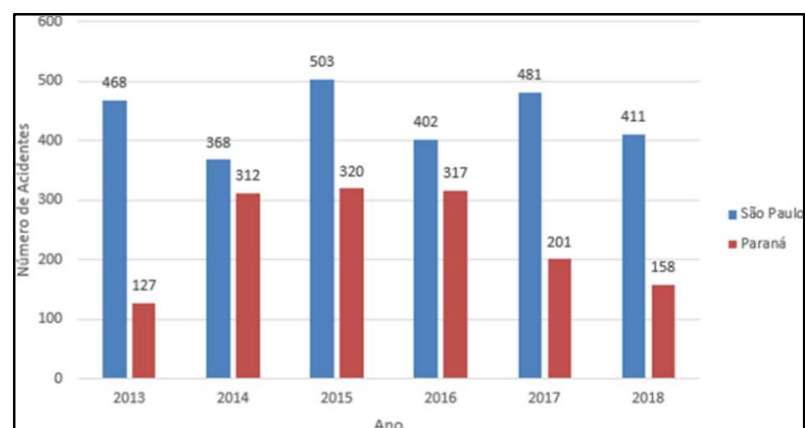

Figura 9: Comparativo do número de acidentes - São Paulo (SP) e Paraná (PR)(Atividade de apoio à agricultura).

Para atividade de apoio à agricultura as regiões que mais se destacaram na questão foram o Sudeste e Sul do país. Os estados que mais se destacaram foram o estado de São Paulo (SP) e o estado do Paraná (PR). Na tabela 8 são apresentados o número de acidentes médios para cada estado e a proporção em suas respectivas regiões.

Na figura 9 é apresentado o número de acidentes cadastrados nos dois estados e é possível notar que os números de acidentes para o estado de São Paulo (SP) permaneceram de certa forma constante, apresentando apenas pequenas flutuações, mas no estado do Paraná (PR) foi observado um aumento no número de acidentes cadastrados entre os anos de 2014 a 2016, no entanto nos anos consecutivos foi obtida quedas sucessivas no número de acidentes registrados.

Embora a ocupação apresente a mesma designação no CBO (Classificação Brasileira de Ocupações) o perfil dos acidentes e dos acidentados apresentou diferenças ao analisar os dados do AEPS e do Smartlab. Para o estado de São Paulo (SP) as lesões mais recorrentes foram contusões e esmagamento de membros, seguido de fraturas. As regiões mais afetadas foram as mãos e pés, e os grupos de agentes causadores mais 
proeminentes foram queda em altura, pelo uso de escadas e trabalho em terrenos não nivelados. Os agentes biológicos vêm como o segundo maior motivo de acidentes pelo contato com animais peçonhentos.

Tabela 8: Comparação entre regiões e estados para a atividade de apoio à agricultura.

\begin{tabular}{|l|l|l|l|l|l|}
\hline $\begin{array}{l}\text { Atividade de apoio à agricultura } \\
\text { (Sudeste) }\end{array}$ & \multicolumn{4}{l|}{$\begin{array}{l}\text { Atividade de apoio à agricultura } \\
\text { (Sul) }\end{array}$} \\
\hline Estado & Proporção & Média & Estado & Proporção & Média \\
\hline SP & $67,06 \%$ & 439 & PR & $62,39 \%$ & 239 \\
\hline MG & $29,75 \%$ & 195 & SC & $20,34 \%$ & 78 \\
\hline ES & $2,26 \%$ & 15 & RS & $17,26 \%$ & 66 \\
\hline RJ & $0,91 \%$ & 6 & & & \\
\hline
\end{tabular}

A ocupação que mais apresentou acidentes foi o trabalho no cultivo de árvores frutíferas, com $51 \%$ de todos acidentes cadastrados para atividade de apoio à agricultura. Para o estado do Paraná (PR) as lesões mais recorrentes foram corte e dilaceramento de membros superiores em sua maioria, afetando as mãos, dedos e olhos. $\mathrm{O}$ grupo de agentes causadores foram à utilização de ferramentas manuais, como faca, facões e ferramenta manual sem força motora. A ocupação que mais se acidentou no estado do Paraná (PR) foi o trabalhador de cana de açúcar.

Essa diferença no perfil dos acidentes e nos acidentados depende da dinâmica econômica de cada estado. Além disso, a análise dos tipos de acidentados para atividades de apoio à agricultura ilustra de certa forma a carência na segurança dos trabalhadores do campo. Um exemplo é o estado do Paraná (PR) que não apresenta uma tradição no cultivo de cana de açúcar, mas grande parte dos acidentes para apoio à agricultura ocorrem no cultivo da cana-de-açúcar. O mesmo raciocínio pode ser aplicado ao estado de São Paulo (SP).

O índice de incidência para cada 1000 vínculos médio para o estado de São Paulo (SP) é de 9,90 e para o estado de Paraná (PR) é de 18,55. Ambos os valores podem ser considerados baixos em comparação a todas atividades analisadas.

\section{CONCLUSÕES}

Ao analisar os Anuários Estatísticos da Previdência Social (AEPS) com dados dos anos de 2013 a 2018 para as 5 atividades na agricultura foi observado que os números de acidentes se encontraram em queda, principalmente acidentes típicos. Nos outros tipos de acidentes essas reduções não foram demonstradas em uma tendência clara, chegando a casos de haver grandes flutuações de um ano em relação a outro. Os motivos não são descritos nos relatórios da AEPS, mas um possível motivo dessas variações é o difícil enquadramento dos acidentes ocorridos como acidentes do trabalho, que é o caso de acidentes de trajeto que são confundidos como acidentes de trânsito, e também o controle dos riscos no setor da agricultura.

O perfil dos acidentados segue um padrão bastante claro, geralmente quem se acidenta nas ocupações estudas são homens que apresentam baixo nível de instrução, e desempenham atividades que estão em contato direto com a atividade do campo. A maioria dos ferimentos ocorrem nos membros superiores, como em mãos e dedos. Os tipos de ferimentos mais comuns encontrados são fraturas, dilacerações e esmagamento.

No entanto, uma das limitações deste estudo foi a falta da disponibilização de informações 
importantes, como tempo de atuação na função, se o trabalhador fazia o uso de equipamentos de segurança quando ocorreu o acidente e se o acidente ocorreu no começo, meio ou fim da jornada de trabalho, podendo nesse último caso avaliar se o acidente foi atribuído ao cansaço ou a desatenção do colaborador.

Outro ponto de bastante relevância para o estudo foi a grande participação dos estados de São Paulo (SP), Mato Grosso (MT) e Mato Grosso de Sul (MS) na participação dos acidentes no meio agrícola. Em números absolutos esses estados apresentaram as maiores ocorrências de acidentes em atividades na agricultura. Isso mostra o quão importante é a ação nestes estados para a redução dos acidentes do trabalho no setor agrícola do país, onde a concepção de programas para a redução nos acidentes pode gerar impactos significativos, uma vez grande parte dos acidentes estão concentrados nesses 3 estados. Além disso, a concepção de um programa que atenda todas as exigências de segurança e considere a peculiaridade dos estados torna-se facilitada, devido a essa concentração regional.

Os resultados desse estudo reforçam alguns pontos de vistas de trabalhos anteriores e ainda dá um panorama geral dos acidentes no meio agrícola. Reforçando a necessidade de políticas nas esferas públicas e privadas para a conscientização dos trabalhadores, e buscando sempre tomar ações para a prevenção dos acidentes. O estudo também buscou relacionar a atividade econômica agrícola dos estados com as ocorrências de acidentes, onde, geralmente, quanto maior for atividade econômica, maior será a ocorrência de acidentes.

\section{REFERÊNCIAS}

FERREIRA, N. S.; MATOS, G. F.; ROUWS, J. R. C.; REIS, V. M.; ROUWS, L. F. M.. Inoculação com rhizobium sp. acelera a brotação de minitoletes de cana-de-açúcar cultivar RB867515. In: SIMPÓSIO NACIONAL DE ESTUDOS PARA PRODUÇÃO VEGETAL NO SEMIÁRIDO, 3. Anais. Campina Grande: Sociedade Científica do Semiárido Brasileiro, 2018.

HERRERA, C. A.. Intervenções em saúde e segurança do trabalho no setor sucroalcooleiro no estado de São Paulo (2004-2013): uma perspectiva qualitativa sobre a percepção de diferentes atores envolvidos. Tese (Doutorado em Engenharia Agrícola) - Universidade Estadual de Campinas, Campinas, 2019.

IBGE. Instituto Brasileiro de Geografia e Estatística. Agricultura e pecuária: produção agrícola municipais culturas temporárias e permanentes. Rio de Janeiro: IBGE, 2020.

NASCIMENTO, D. C. G. A.; PIGNATTI, M. G.; LEÃO, L. H. C.; OLIVEIRA, Â, L. P.; SILVA, A. M. C.. Health, work, and development: agribusiness and accidents in a state in the Brazilian Amazon region. Cadernos Saúde Coletiva, v.24, n.3, p.286-293, 2016. DOI: https://doi.org/10.1590/1414$\underline{462 \times 201600030154}$

NOCELLI, R. C. F.; ZAMBON, V.; SILVA, O. G. M.; MORINI, M. S. C.. Histórico da cana-de-açúcar no Brasil: contribuições e importância econômica. In: Cana-de-açúcar e seus impactos: uma visão acadêmica. 2017. p.13.
SANTOS, V.. Fator acidentário de prevenção: custo ou benefício?. Engenharia de Segurança do TrabalhoFlorianópolis, 2017.

SIEMINKOSKI, T.. Acidentes de trabalho no Brasil de 2007 a 2015: indicadores e previsão de acidentes. Dissertação (Mestrado) - Universidade Tecnológica Federal do Paraná, Curitiba, 2017.

SILVA, A. V. P.. Análise de dados estatísticos municipais de acidentes do trabalho ocorridos no estado do Rio Grande do Norte entre 2015 e 2016. Monografia (Bacharelado em Ciência e Tecnologia) - Universidade Federal Rural do Semiárido, Angicos, 2019.

SILVA, T. F. O.; RUMIN, C. R.. Acidentes de trabalho no processamento industrial da cana-de-açúcar. Revista OMNIA Saúde, v.13, n.2, p.18-26, 2017.

SOUSA, F. N. F.; SANTANA, V. S.. Mortalidade por acidentes de trabalho entre trabalhadores da agropecuária no Brasil, 2000-2010. Cadernos de Saúde Pública, v.32, p.e00071914, 2016.

ZAWACKI, M. P.. Acidentes de trabalho ocorridos no meio rural na comunidade de Espírito Santo, Alegria, RS. Monografia (Tecnológico em Desenvolvimento) Universidade Federal do Rio Grande do Sul, Três de Maio, 2017.

A CBPC - Companhia Brasileira de Produção Científica (CNPJ: 11.221.422/0001-03) detém os direitos materiais desta publicação. Os direitos referem-se à publicação do trabalho em qualquer parte do mundo, incluindo os direitos às renovações, expansões e disseminações da contribuição, bem como outros direitos subsidiários. Todos os trabalhos publicados eletronicamente poderão posteriormente ser publicados em coletâneas impressas sob coordenação da Sustenere Publishing, da Companhia Brasileira de Produção Científica e seus parceiros autorizados. Os (as) autores (as)

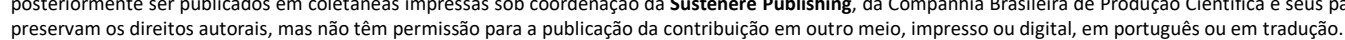

